\title{
A framework for business model development in technology-driven start-ups
}
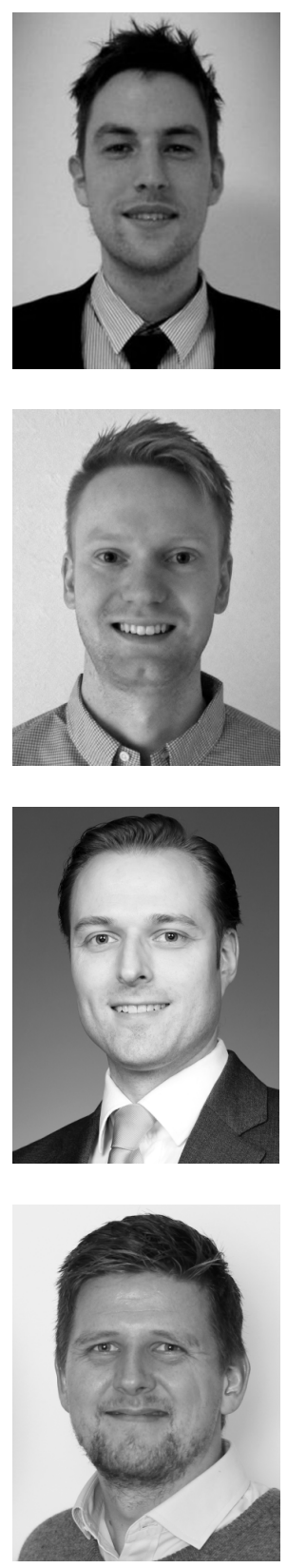

Kristian Groth Albøge, Jesper Gyldenlev Andersen, Rainer Lueg, Kristian Posselt Nielsen

Geschäftsmodellentwicklung; junge Unternehmen; Analyserahmen; Entscheidungsfindung; Umweltunsicherheit; Planung.

Business Model development; start-up; framework; decision making; environmental uncertainty; planning.

Dieser Beitrag analysiert, wie sich Geschäftsmodelle in jungen Unternehmen entwickeln lassen und stellt einen Analyserahmen vor. Um einen Praxisbezug zu gewährleisten wird eine Fallstudie aus einem jungen skandinavischen Unternehmen durchgeführt. Eine Erkenntnis hieraus ist, dass die Geschäftsmodellliteratur bisher keinen konsistenten Erklärungsansatz für die Geschäftsmodellentwicklung in jungen Hochtechnologieunternehmen bietet. Diese Lücke besteht, da zumeist von linearen Entscheidungsprozessen ausgegangen wird, die dem Verständnisprozess des Unternehmens in Bezug auf seine Umwelt nicht gerecht werden. Der entwickelte Analyserahmen erklärt wie junge Unternehmen zunächst iterativ und pfadabhängig Geschäftsmodellprototypen entwickelt, bevor es diese taktisch ausgestaltet.

We propose a framework to explain how business models develop in technology-driven start-up companies using a case study from Scandinavia. We suggest that existing frameworks assume a linear decision process that ignores the company's course of experimenting under environmental uncertainty. Our proposed framework acknowledges how a start-up makes several iterative and path-dependent decisions to create several business model prototypes before eventually making the irreversible strategic choice of which one to implement.

\section{Introduction}

Business models have received much attention in contemporary research (Zott et al. 2011). In particular, researchers try to understand how business models help transform innovations into commercial products and services, and ultimately into economic value (Chesbrough/Rosenbloom 2002; Chesbrough 2007; Zott/Amit 2007; Sosna et al. 2010). The literature differentiates between two types of changes that are caused by innovation (Cavalcante et al. 2011). The 
first is the extension or revision of a business model in a mature company (Nielsen/Lund 2012). This stream of research mainly focuses on established businesses which adapt to changes, e.g., in technology, customer preferences, competitors, and substitute products. This study focuses on the second type, which is the creation of a new business model based on a new technology in a start-up company. We define technology-driven start-ups as companies that are either newly founded by an entrepreneur (Zott/Amit 2007) or spun off by a mature organization (Chesbrough/Rosenbloom 2002) to commercialize a 'technological' innovation—as opposed to 'process'/'service' innovations (Teece 2010). While entrepreneurial companies and spin-offs differ in some aspects, both try to commercialize "technologies in search of a market" (George/Bock 2011, 102). This similarity makes findings on the development of business models relevant for both types of companies (similar: Doganova/Eyquem-Renault 2009).

However, there is little evidence on the development of business models in start-ups and the way they translate a technological innovation into an innovative, value-adding solution for customers (Muegge 2012; Trimi/Berbegal-Mirabent 2012). Zott and Amit (2007) and Chesbrough (2007) highlight that business model development is crucial to the commercial success of entrepreneurs but that a framework is needed to facilitate this development process. While Zott and Amit (2007) discover a positive effect of novelty-centred business models for start-ups, they call for a better understanding of how business models evolve in the first place. Several authors conjecture that this lack of knowledge is due to the absence of a framework that explains the development of business models (Morris et al. 2005; Sosna et al. 2010; George/Bock 2011). It is our goal to propose such a framework to guide practice and to improve comparability among studies.

We address this question by conducting a qualitative, exploratory single-company case study in a Scandinavian start-up that spun off from a university-based research group. This start-up intends to use nano-fibres to tag expensive goods, so an end consumer can easily verify their authenticity. We find that the linear way of thinking in existing models does not match the realities of such a technology-driven start-up that acts under environmental uncertainty. Our new framework accounts for the iterative and path-dependent decision making processes to design several business models — what we coin-'prototypes' before the business model reaches its target market. The majority of the literature describes business model development as a process where a single business model is vaguely outlined in the entrepreneur's mind and becomes clearer as the start-up matures (Morris et al. 2005). We contribute to the work of those authors who acknowledge that there are competing prototypes among which entrepreneurs choose: Sosna et al. $(2010,384)$ refer to them as "alternative business model variants", Teece $(2010,187)$ as "templates", and Chesbrough (2010, 354) as "experimentation".

The structure of the paper is as follows: section 2 reviews the foundations of our research field and drafts a framework for business model development. Section 3 elaborates on the methodology, and section 4 presents an example. Section 5 discusses the implications of our newly developed framework and explores future research possibilities.

\section{Literature review on business models: components or processes?}

Our literature review has been conducted based on our expert knowledge on business models. We searched the databases ScienceDirect and EBSCO for the terms "business model creation" and "business model development" in combinations with "technology", 
"entrepreneur", "venture", and "start-up". We also used Google Scholar to check for sources citing seminal articles to identify the most contemporary literature. Hence, this literature review is an expert review that aims for relevance, not a systematic review that aims for completeness in the sense of Denyer and Tranfield (2009). The latter generally requires a separate study (examples include Lueg/Carvalho e Silva 2013; Albertsen/Lueg 2014).

According to Zott et al. (2011), the literature lacks a common definition of business models, which is partly due to the novelty of the research field. There are many possible ways to structure this field of research, such as by topics (Zott et al. 2011). We noticed that the business model literature can alternatively be structured by their components and their processes. The 'component' literature aims at describing what a business model is by stating which components need to be accounted for (Amit/Zott 2001; Magretta 2002; Johnson et al. 2008; Osterwalder/Pigneur 2010). Many of these definitions overlap. As a seminal example, the very popular business model canvass by Osterwalder and Pigneur (2010) states that a business model must account for nine building blocks to be successful: key activities; key partners; key resources; cost structure; customer relationships; customer segments; value proposition; channels; revenue streams.

DaSilva and Trkman (2014) criticize the component literature as overly descriptive. They propose that not resources by themselves but transactions explain how resources create value. They define business models as chains of short-term choices a manager must make to implement the company's long-term strategy. This leads to another stream of literature that focuses on the interactions between a company's resources and hence looks at business models from a process perspective. These works do not prescribe which components should be included but explain which steps a company should follow to develop an effective business model. Osterwalder and Pigneur (2010, 250) also acknowledge this perspective and introduce a business model design process of five stages; mobilize, understand, design, implement, and manage. A seminal work in this stream of literature is Casadesus-Masanell and Ricart (2010,296), who define a business model as "the logic of the firm, the way it operates and how it creates value for its stakeholders." Thus, the authors do not see the business models as a list of components but rather as choices and their consequences. As to the choices, Casadesus-Masanell and Ricart (2010) distinguish between a strategic and a tactical stage. In the strategic stage, a range of possible business models are available. Choosing a business model in the strategic stage then limits the options in the more concrete, tactical stage. Thus, Casadesus-Masanell and Ricart (2010, 196) refer to tactics as the residual choices open to the company. The authors describe their framework of choices and consequences as the "generic two-stage competitive process framework". Their view on business model development-i.e., continuous choices for re-adjustment and experimentation-is in line with several recent papers on this topic, such as Sosna et al. (2010) and Cavalcante et al. (2011). Furthermore, CasadesusMasanell and Ricart (2010) implicitly assume a causal linkage between choices and their consequences. It is of importance to verify these causality assumptions (Shafer et al. 2005), but such causal relationships in business models have only been empirically tested to a limited extend (Zott/Amit 2007; Huelsbeck et al. 2011). Despite its shortcomings, we initially adopt the view of Casadesus-Masanell and Ricart (2010) to develop our framework.

Environmental uncertainty comprises several sub-constructs such as dynamism or munificence (cf. Borisov/Lueg 2012; Lueg/Borisov 2014). It generally indicates changes in the 
environment (e.g., in customer needs, production technology, competition, pricing) relevant to a business that are unpredictable. Chesbrough and Rosenbloom $(2002,532)$ explicitly account for the fact that external uncertainties (e.g., technology or the market) affect the translation from technological input to economic output (also: Zott/Amit 2007; Cavalcante et al. 2011). Their ideas are picked up by the empirical study of Andries and Debackere (2007) on 117 technology-driven start-ups. The authors uncover that adjusting business models to environmental uncertainty increases survival rates. Their study is not directly transferable to our case since the authors assume a non-disruptive development of the same business model (p. 83). Also, Andries and Debackere (2007, 84) investigate specific industry effects of uncertainty. However, Mangematin and Walsh (2012) point out that nano-technology is a cross-industry technology. Furthermore, Andries and Debackere (2007, 88) measure business models development ("adaptation") only as a change of the target market. Yet, the authors encourage detailed investigation of why and how business models are developed under uncertainty. This is what we intend to do in this case study. Likewise, George and Bock (2011) call for studies of business model development that describe interactions with the opportunity landscape. Morris et al. (2005) suggest investigating a business model's fit with changing environmental conditions. Finally, Sosna et al. (2010) highlight that entrepreneurs need a trial-and-error process in order to learn about the optimal fit of the business model with the environment.

\section{Methodology}

\subsection{Choice of the case study method}

We conduct a single-company case study to propose a preliminary framework for business model development in technology-driven start-ups. The case study method is appropriate for capturing processes in a detailed way (Yin 2009). Also, insights from case studies are closely linked to empirical data, so case studies are likely to possess sufficient validity and reliability (Gibbert et al. 2008; Yin 2009). We ensure internal validity by discussing the most appropriate notion of business models, matching it to patterns observed by previous authors, and triangulating the interview with publicly available data. Related to this, we provide construct validity by guiding the interview toward established notions of business models. Our generalizations are only 'analytical' to back up our framework, which startups and researchers could use in the future. We do not generalize 'statistically' across the population of start-ups. Additionally, single-company case studies with little interview material are an accepted method in contemporary research on entrepreneurial business models, even in leading academic journals (examples are Doganova/Eyquem-Renault 2009; Sosna et al. 2010; Lueg et al. 2013; Dalby et al. 2014; Lueg et al. 2014; Malmmose et al. 2014). Lastly, we ensure procedural reliability by describing our research procedures.

\subsection{The case company NanoTAG}

We use the company NanoTAG (real name is disguised), which is a technology-driven start-up company based in Scandinavia. We gained access to NanoTAG by scanning the university technology park's website for technology-driven start-ups. NanoTAG appeared suitable to us: Mangematin and Walsh (2012) claim that nano-technology is versatile in its applicability. This makes decisions under uncertainty about very different business models more likely. 
NanoTAG can create physical tags that are invisible to the human eye and consist of nano-fibres. Nano-fibres are microscopic strings created through heating of inorganic fertilizer in vacuum chambers. This makes the fibres form unique patterns depending on how the process is performed. The tag is then stored in a central database, assigned to a product, and can be verified using a high-resolution camera, which could possibly be integrated into smartphones. NanoTAG also develops the necessary apps. According to NanoTAG, this technology may be relevant for a wide range of customers to ensure the authenticity of products, such as luxury brands (e.g., electronics, clothes, jewellery, accessories), high-end pharmaceuticals, and federal reserves (currency bills).

The discovery of this technology in 2009 was serendipitous. It took place after experimenting with photovoltaic cells at a Scandinavian university. In 2012, NanoTAG spun off the original laboratory to develop the technology in a more entrepreneurial setting. NanoTAG still cooperates with the university and receives funds from there as it does not create any revenue yet. For us, this was the optimal point to enter the company as NanoTAG was just in the process of leaving the university incubator to commercialize its ideas. Maine, Lubik and Garnsey (2012) describe this search for such opportunities as quite complex as nanotechnology is often praised, but its practical applications prove difficult. NanoTAG had just progressed so far that it was possible to present a product and investigate price sensitivity in the market. The CEO was working with three different future business models; in-house production of tags, selling production licenses, and outsourcing the production in order to operate as a sales company. The road to commercialization of nano-tags for verification-purposes had therefore been initiated, and contacts had been made to potential partners in respect to application and pricing.

\subsection{Data collection}

Our primary data source is an interview with NanoTAG's CEO during the summer of 2013. The CEO has a PhD and an MSc in physics as well as an MBA. We chose an interview because it can provide knowledge about the topic and the relationship between its sub-topics (Yin 2009). The interview was semi-structured to ensure that all relevant topics were covered while still granting flexibility to explore alternative new paths. We developed our interview protocol along the interactions that NanoTAG has with relevant actors. These include the university / technology park hosting them, investors, target customers, producers of supplement products (e.g., smartphone cameras), and competitors / producers of substitute products that would interfere into these relationships. The interview with the CEO lasted 102 minutes and was conducted by two of the authors in the native Scandinavian language. It was audio-recorded, transcribed, and then translated into English. Our secondary data sources were the publicly available data on the web, such as NanoTAG's own website and other websites reporting about NanoTAG. These sources corroborated what the CEO told us in his interview.

\section{Findings: a framework for business model development in technology-driven start-ups}

We now use the case of NanoTAG to propose a framework for business model development in technology-driven start-ups and locate NanoTAG's current position in this frame- 
work. Our framework is depicted in Figure 1. We will elaborate on its parts in the following sub-sections.

Figure 1: Framework of business model development in start-up companies

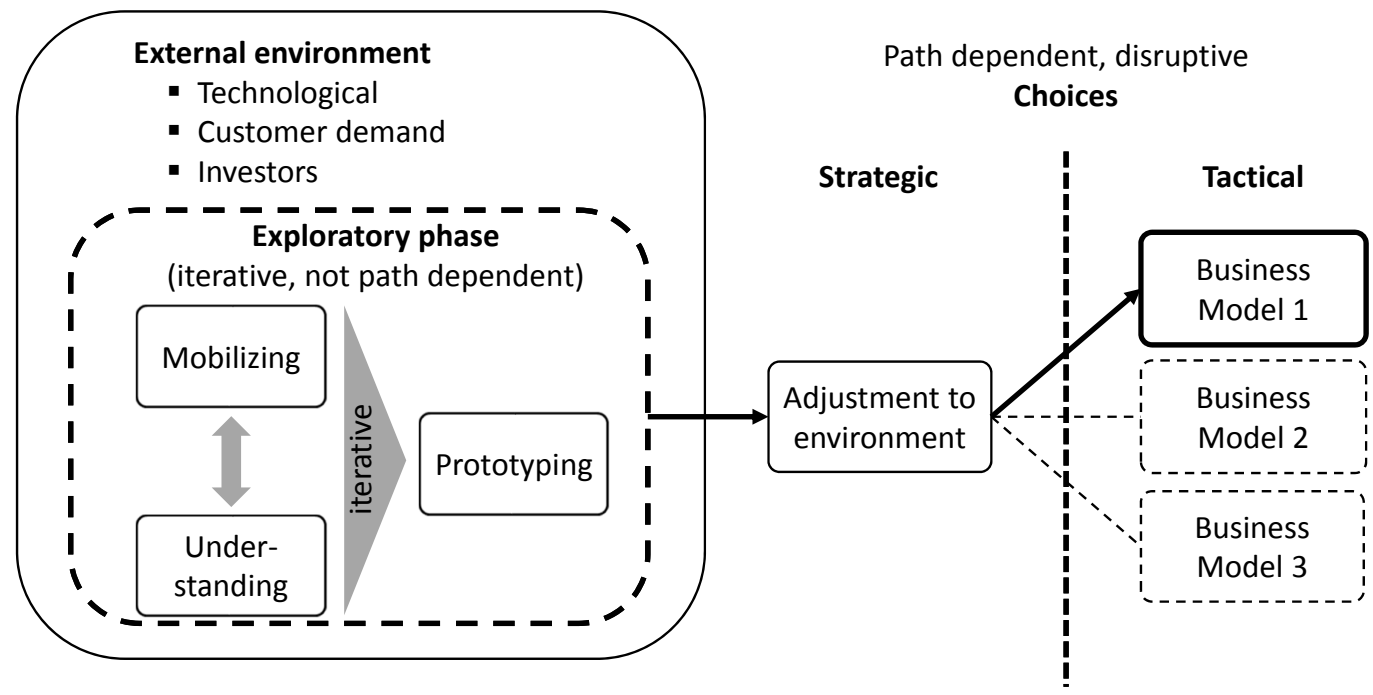

\subsection{Exploratory phase}

NanoTAG started its business model development with an internal view on its current resources, i.e., its unique technological innovation. It tried to gain insights into the possibilities of this technology and filed the corresponding patents. This corresponds to the first stage of Osterwalder and Pigneur's (2010) design process (mobilize).

"Maybe there was an overly strong focus on technology and demonstrating how it works. [...] I have been given this job to demonstrate our focus on technology. So the scale has been clearly tipped toward technology in the beginning, you can make a note of that!"

Then, the CEO has shifted the focus toward the market and the applications of the technology.

"Right now there is clear focus on presenting the business and the product [...]. It is a crystal clear market focus.”

The company started gaining insights into potential markets, customers, and the environment. This corresponds to the second stage (understand) of Osterwalder and Pigneur (2010). The CEO outlined three alternative business models in the interview to choose from: 1) establish in-house production and sales of nano-tags, 2) outsource production and build up an internal sales organization, and 3) ensure best ownership and sell the company to an established company.

This could be seen as designing business model prototypes. Our observation supports Osterwalder and Pigneur (2010) that the understanding and designing stages often tend to 
advance in parallel (hence the two-directional arrow in Figure 1). On the surface, the three first stages of Osterwalder and Pigneur's (2010) business model design process seem to capture NanoTAG's development. However, Osterwalder and Pigneur (2010) do not elaborate on the difficulty of making decisions under uncertainty, which makes it suitable for mature companies rather than for start-ups. To NanoTAG, it was not clear whether certain resources, customer demands, and partners would be available once the choice for one of the business model prototypes had been made.

The third part of this exploratory phase was the development of prototypes. This roughly corresponded to the third stage (design) of Osterwalder and Pigneur (2010) but acknowledged that there was more than one path that the start-up would explore under uncertainty. We generally suggest that prototypes are the result of mobilizing and understanding while allowing for an iterative process.

\subsection{External environment}

This part of the framework reflects a company need to account for environmental uncertainty (dashed lines to indicate permeability). One of the distinct arguments of Chesbrough and Rosenbloom (2002) is the existence of external uncertainties, which influence how the technical inputs are converted into economic output (also cf. Wirtz et al. 2010; Cavalcante et al. 2011). Regarding NanoTAG, uncertainty on technology and market conditions constrained informed decisions on the business model prototypes. To mitigate uncertainty, the CEO focused on potential market segments. He discussed how the market focus helped the company understand costumer needs, thereby acquiring insight into relevant attributes of the technology. Another source of technological uncertainty is if supplement products like smartphone cameras will be sufficiently developed to be able to recognize nano-fibers. As the CEO states:

"Actually, we do not even know if the high-resolution cameras needed to detect nanofibers will even be a standard in near-future smartphones. Probably, [smartphones] would require a micro-lens. Anyway, it would not cost much. Some customers might even deliver it for free with their product. I do not know, but again, we must see how [camera] technology has developed in the market when we get there."

The feedback the CEO received from potential costumer interviews was crucial in developing the business model, especially how to configure value proposition and cost/revenue models. The CEO indicated that there were several paths to choose between which all require substantial investments into different infrastructures. This highlights the disruptive nature of strategic decisions that are opposed to a gradual, smooth development of a business model in start-ups:

„Again, it's [the revenue model] all about the dialogues we have with the customers. There are so many possibilities. The tag could be free, but then we charge the end consumer for the use of the app. Or we charge our clients for getting their product into our database, and then they can also monitor their products. We thought about it a lot, and we will be very receptive during the course of our work. But we have not decided on which road to take."

Moreover, NanoTAG could not implement any prototype due to limited funds. The company had a tight schedule set by its investors as indicated by the CEO: 
"There are of course some expectations of what to do. But there is also only a limited amount of money. And with this limited amount of money, we shall accomplish the result that the investors paid for."

Another uncertainty the CEO tried to reduce was on the maturity of the technology. Because of these uncertainties, it was not possible to foresee all possible business models, and a trial-and-error approach was therefore relevant (Chesbrough/Rosenbloom 2002). This is an important insight when deriving a new framework on business model development in technology-driven start-up companies.

"There is a comprehensive set of different technologies for this here [NanoTAG's invention]. What we need to do is create a business model around it for customers that need reliable proof of authenticity for different goods. For now, we are in a situation where we are looking into the future, and we still have so many options of how to transform our technology into a product. We do not fully know how our various possible customers will work with the tags. So we have not decided on how to price an individual tag. [...] What I am doing now is getting out of the lab and knocking on some doors; I am discussing our technology with potential customers, and try to understand what they need."

In conclusion, we propose that uncertainty needs to be taken into account more thoroughly when describing business model development in start-ups. We make three standard suggestions of which issues to address (technological change; customer needs; investor expectation). But these can be extended or limited in future studies.

\subsection{Strategic choice and the chosen business model}

Adjusting the exploratory phase of mobilizing, understanding, and creating prototypes to the external environment will lead to an array of strategic choices (indicated by the curved box). This corresponds to the two-stage competitive process framework by CasadesusMasanell and Ricart (2010). The exploratory phase was characterized by a high degree of flexibility allowing multiple prototypes to be tested trough trial-and-error. After the strategic choice has been made, the flexibility will decrease significantly since the committed choice lays out the general path which future choices are dependent on. This conclusion is supported by Chesbrough and Rosenbloom's $(2002,536)$ notion that "the choice of business model constrains other choices, filtering out certain possibilities". In our framework, a strategic choice is not just any choice as in Casadesus-Masanell and Ricart (2010). We argue that it must be so substantial that the company has almost reached a point of no return, e.g., by actually selling the entire operations to a best owner (the dotted line indicates that there are irreversible elements in such decisions). Otherwise, the company is still in the exploratory phase.

The extant literature on mature companies depicts business model development as gradual. Our start-up-specific framework highlights that there are disruptions caused by irreversible choices. Our more radical view reflects that entrepreneurs often "try to find fundamentally new ways of doing business that will disrupt an industry's existing competitive rules, leading to the development of new business models" (Ireland et al. 2001, 53). 


\subsection{The development of the business model of NanoTAG so far}

If a business model is a set of connected choices (Casadesus-Masanell/Ricart 2010), one might argue that NanoTAG does not yet have a business model: the company picked its technology and made the choice of getting funded by the university's incubator. But connected choices as to concrete customer or the revenue model are still open. Alternatively, one might argue that NanoTAG has a complete business model: Casadesus-Masanell and Ricart (2010) propose a two-step process where all considerations concerning later tactical business model choices are already assessed in the strategic stage. These assessments are always made under uncertainty. Therefore, it is not possible to determine the content of the business model all at once. In this sense, NanoTAG's notion of its business model could be considered a full business model despite not having customer relations yet.

It is a strength of Casadesus-Masanell and Ricart (2010) that they explain this path-dependent transition from the strategic to the tactical stage where many components of the business model cannot yet be completed. As choices are made, their consequences limit the flexibility of the future decisions. For instance, NanoTAG's choice of financing limits the investment policy of NanoTAG, as investors want influence on the direction of the company.

Yet, we also see some problems in the application of the business model framework of Casadesus-Masanell and Ricart (2010) since it assumes a linear two-step process, whereas hundreds of singular decisions, in reality, move NanoTAG toward the tactical stage of its business models. Some of these decisions have been considered and implemented (such as the product prototype), whereas others are still hypothetical (e.g., customer segments and pricing). In addition, the process of determining which decisions can be made and which ones still need to wait often appeared to be out of the hands of NanoTAG. This degree of randomness and lacking controllability is not accounted for in current frameworks. Our framework can account for the fact that NanoTAG is actually in between the strategic and the tactical stage.

\section{Discussion}

We propose a new framework for business model development in technology-driven startup companies. The framework incorporates the strengths that have been identified from existing literature and provides start-ups with a structured view on early business model development. We build on stages of business model development proposed by Osterwalder and Pigneur (2010), which are mobilizing, understanding, and prototyping business models. These stages are linked in a flexible, circular process making it easier to adapt to external contingencies. The chosen contingencies are based on the work of Chesbrough and Rosenbloom (2002). This exploratory process enables the start-up company to make a strategic choice between possible business models as suggested by CasadesusMasanell and Ricart (2010). We make several contributions to practice and research.

\subsection{Implications for practice}

A first insight for practice is that this exploratory phase of back-and-forth is not a weakness for a start-up, and it does not represent an underdeveloped business model. We argue that this phase is actually of high importance to the understanding of uncertainties that affect the ultimately chosen business model, since this increases a start-up's chances of sur- 
vival (Andries/Debackere 2007). Business model development should be devoted to mobilize resources, understand the business environment, and design business model prototypes. Companies can attempt to structure the process linearly, but often these attempts will be unrewarding due to technological, market, and financial uncertainties. Rather than attempting to control a dynamic environment, companies could exploit the dynamism by having a flexible business model development that can easily adapt and thereby exploit opportunities faster than established companies.

A second insight for start-ups is that irreversible decisions have to be made at some point. George and Bock (2011) highlight that the role of a business model is to narrow down the opportunities of an entrepreneur toward the most suitable goal and to limit the field in which a company is active. In line with this, we propose that a business model prototype can only be realized after a leaping strategic decision has been made, such as starting operations or finding new partners. As these strategic decisions will limit the wide array of opportunities that start-ups need to consider the effects of path dependency when making early strategic choices. This is in line with the argument of Chesbrough and Rosenbloom (2002) who argue that the value of most technologies remains latent until they are commercialized. Our framework is also an advancement of the idea that entrepreneurs have the eventual business model, which only becomes clearer over time.

\subsection{Implications for research}

One of the major contributions of our framework over existing literature is the non-linear exploratory phase (Osterwalder/Pigneur 2010; Sosna et al. 2010; Cavalcante et al. 2011). This phase represents the gathering of information which lays out the foundation of the strategic choice (Casadesus-Masanell/Ricart 2010; DaSilva/Trkman 2014). We thereby show a link to the well-explored field of strategic decision. Our framework can serve as a basis for further research on business model development. Our framework particularly provides links to two established lines of thought:

First, the iterative nature of the exploratory phase corresponds to strategic thinking: Simon (1960) identifies three major elements of decision making: 1) finding occasions for making a decision, 2) finding possible courses of action, and 3) choosing among courses of action. For instance, the circular process of mobilizing, understanding, and prototype represent the company's attempt to identify possibilities of action, and the strategic choice represents the choosing of action. Thus strategic planning and decision making also interact in our business model development framework.

Second, our framework is linked to bounded rationality (Simon 1965). The exploratory phase provides the information input for the strategic choice. In the choice of a business model, too many contingencies exist for the decision maker to comprehend them all. Therefore, he is forced to act based on information available.

Lastly, the relevance of uncertainty for business model development has been mentioned by several authors (Chesbrough/Rosenbloom 2002; Morris et al. 2005; Zott/Amit 2007; Sosna et al. 2010; Teece 2010; Cavalcante et al. 2011; George/Bock 2011). Yet, very few studies explicitly address this relationship in their study design (e.g., the commendable study by Andries/Debackere 2007). We identify specific sources of uncertainty (technological development in the market, customer needs, as well as the expectations of investors) and relate them to the business model development in a start-up. 


\subsection{Limitations and future research}

We derive our framework alongside a single-company case study (Yin 2009). This suggests that the findings of this paper can only be generalized 'analytically'. To generalize 'statistically' for a wider group of start-ups, empirical tests of our framework are needed. We suggest multiple case studies of companies at different points of the technology- vs. marketdriven continuum (Sánchez/Ricart 2010). Also, longitudinal studies would provide a more holistic view of the business model development, so the ultimately chosen business model can be compared to the prototype.

Another interesting avenue for future research could be to analyse the impact of further uncertainties that did not play a role in our investigations. Other technology-driven startups might be subject to stricter scrutiny by regulation or national laws. Another underexplored factor in our study is the role of competition, since NanoTAG has patented rights to a unique technology.

Lastly, the limited pools of resources available to start-up companies are also an interesting topic for further research. When analysing business model development, the idea of open business models would suggest more cooperation with stakeholders that might mitigate some of the resource scarcity (Trimi/Berbegal-Mirabent 2012).

\section{References}

Albertsen, O. A./Lueg, R. (2014): The Balanced Scorecard's missing link to compensation: a literature review and an agenda for future research, in: Journal of Accounting and Organizational Change, 10(4), 431-465.

Amit, R./Zott, C. (2001): Value creation in e-business, in: Strategic Management Journal, 22(6-7), 493-520.

Andries, P./Debackere, K. (2007): Adaptation and performance in new businesses: Understanding the moderating effects of independence and industry, in: Small Business Economics, 29(1-2), 81-99.

Borisov, B. G./Lueg, R. (2012): Are you sure about what you mean by 'uncertainty'? The actor's perspective vs. the institutional perspective, in: Proceedings of Pragmatic Constructivism, 2(2), 51-58.

Casadesus-Masanell, R./Ricart, J. E. (2010): From strategy to business models and onto tactics, in: Long Range Planning, 43(2-3), 195-215.

Cavalcante, S./Kesting, P./Ulhøi, J. (2011): Business model dynamics and innovation:(re) establishing the missing linkages, in: Management Decision, 49(8), 1327-1342.

Chesbrough, H. (2007): Business model innovation: it's not just about technology anymore, in: Strategy \& Leadership, 35(6), 12-17.

Chesbrough, H. (2010): Business model innovation: opportunities and barriers, in: Long Range Planning, 43(2-3), 354-363.

Chesbrough, H./Rosenbloom, R. S. (2002): The role of the business model in capturing value from innovation: evidence from Xerox Corporation's technology spin-off companies, in: Industrial and Corporate Change, 11(3), 529-555.

Dalby, J./Nielsen, L. S./Lueg, R./Pedersen, L./Tomoni, A. C. (2014): National culture and business model change: a framework for successful expansions, in: Journal of Enterprising Culture, forthcoming. 
DaSilva, C. M./Trkman, P. (2014): Business model: what it is and what it is not, in: Long Range Planning, 47(6), 379-389.

Denyer, D./Tranfield, D. (2009): Producing a systematic review, in D. Buchanan \& A. Bryman (Eds.): The Sage Handbook of Organizational Research Methods, London, pp. 671-689.

Doganova, L./Eyquem-Renault, M. (2009): What do business models do?: Innovation devices in technology entrepreneurship, in: Research Policy, 38(10), 1559-1570.

George, G./Bock, A. J. (2011): The business model in practice and its implications for entrepreneurship research, in: Entrepreneurship Theory and Practice, 35(1), 83-111.

Gibbert, M./Ruigrok, W./Wicki, B. (2008): What passes as a rigorous case study?, in: Strategic Management Journal, 29(13), 1465-1474.

Huelsbeck, D. P./Merchant, K. A./Sandino, T. (2011): On testing business models, in: The Accounting Review, 86(5), 1631-1654.

Ireland, R. D./Hitt, M. A./Camp, S. M./Sexton, D. L. (2001): Integrating entrepreneurship and strategic management actions to create firm wealth, in: The Academy of Management Executive, 15(1), 49-63.

Johnson, M. W./Christensen, C. M./Kagermann, H. (2008): Reinventing your business model, in: Harvard Business Review, 86(12), 57-68.

Lueg, R./Borisov, B. G. (2014): Archival or perceived measures of environmental uncertainty? Conceptualization and new empirical evidence, in: European Management Journal, 32(4), 658-671.

Lueg, R./Carvalho e Silva, A. L. (2013): When one size does not fit all: a literature review on the modifications of the Balanced Scorecard, in: Problems and Perspectives in Management, 11(3), 86-94.

Lueg, R./Clemmensen, S. N./Pedersen, M. M. (2013): The role of corporate sustainability in a lowcost business model - A case study in the Scandinavian fashion industry in: Business Strategy and the Environment (forthcoming).

Lueg, R./Malinauskaite, L./Marinova, I. (2014): The vital role of business processes for a business model: the case of a startup company, in: Problems and Perspectives in Management, 12(4), 213-220.

Magretta, J. (2002): Why business models matter, in: Harvard Business Review, 80(5), 86-92.

Maine, E./Lubik, S./Garnsey, E. (2012): Process-based vs. product-based innovation: value creation by nanotech ventures, in: Technovation, 32(3), 179-192.

Malmmose, M./Lueg, R./Khusainova, S./Iversen, P. S./Panti, S. B. (2014): Charging customers or making profit? Business model change in the software industry, in: Journal of Business Models, 2(1), 19-32.

Mangematin, V./Walsh, S. (2012): The future of nanotechnologies, in: Technovation, 32(3), 157-160.

Morris, M./Schindehutte, M./Allen, J. (2005): The entrepreneur's business model: toward a unified perspective, in: Journal of Business Research, 58(6), 726-735.

Muegge, S. (2012): Business model discovery by technology entrepreneurs, in: Technology Innovation Management Review(April), 5-16.

Nielsen, C./Lund, M. (Eds.). (2012). Business Models: Networking, Innovating and Globalizing, Copenhagen.

Osterwalder, A./Pigneur, Y. (2010). Business Model Generation: A Handbook for Visionaries, Game Changers, and Challengers, New York, NY. 
Sánchez, P./Ricart, J. E. (2010): Business model innovation and sources of value creation in low-income markets, in: European Management Review, 7(3), 138-154.

Shafer, S. M./Smith, H. J./Linder, J. C. (2005): The power of business models, in: Business Horizons, 48(3), 199-207.

Simon, H. A. (1960). The New Science of Management Decision, New York, NY.

Simon, H. A. (1965). The Shape of Automation for Men and Management, New York, NY.

Sosna, M./Trevinyo-Rodríguez, R. N./Velamuri, S. R. (2010): Business model innovation through trial-and-error learning: the Naturhouse case, in: Long Range Planning, 43(2), 383-407.

Teece, D. J. (2010): Business models, business strategy and innovation, in: Long Range Planning, 43(2-3), 172-194.

Trimi, S./Berbegal-Mirabent, J. (2012): Business model innovation in entrepreneurship, in: International Entrepreneurship and Management Journal, 8(4), 449-465.

Wirtz, B. W./Schilke, O./Ullich, S. (2010): Strategic development of business models: implications of the Web 2.0 for creating value on the internet, in: Long Range Planning, 43(2-3), 272-290.

Yin, R. K. (2009). Case Study Research: Design and Methods (4th ed.), Thousand Oaks, CA.

Zott, C./Amit, R. (2007): Business model design and the performance of entrepreneurial firms, in: Organization Science, 18(2), 181-199.

Zott, C./Amit, R./Massa, L. (2011): The business model: recent developments and future research, in: Journal of Management, 37(4), 1019-1042. 
Kristian Groth Albøge, MSc in Management Accounting and Control, is a Graduate at Svenska Handelsbanken.

Address: Handelsbanken, Østergade 2, DK-7400 Herning, Tel. +45.29919230, E-Mail: kral06@handelsbanken.dk.

Jesper Gyldenlev Andersen, MSc Management Accounting and Control, is currently working as a consultant in the private sector.

Address: Aarhus University, School of Business and Social Sciences, Department of Economics and Business, Fuglesangs Allé 4, DK-8210 Aarhus V, E-Mail: gyldenlev@outlook.com.

Rainer Lueg, Dr. rer. pol., Dipl.-Kfm., Dipl.-Volksw., is an Associate Professor at Aarhus University, School of Business and Social Sciences, Department of Economics and Business.

Address: Aarhus University, School of Business and Social Sciences, Department of Economics and Business, Fuglesangs Allé 4, DK-8210 Aarhus V, Tel. +45.87164969, E-Mail: rlueg@asb.dk.

Kristian Posselt Nielsen, MSc Management Accounting and Control, is a Research Assistant at Aarhus University, School of Business and Social Sciences, Department of Economics and Business.

Address: Aarhus University, School of Business and Social Sciences, Department of Economics and Business, Fuglesangs Allé 4, DK-8210 Aarhus V, E-Mail: posselt86@gmail.com.

Acknowledgements: We acknowledge the contribution of Peter Olav Ahrensbach to this work. 